\title{
The Role of the ESP Teacher in the In-company Training: An Experience in an Oil Exploration and Extraction Company in Cuba
}

\author{
Dora Mirta Troitiño Díaz \\ Department of English for Specific Purposes, Postgraduate School of Energy and Mining, Havana, Cuba \\ Email address: \\ dorita@eem.minem.cu \\ To cite this article: \\ Dora Mirta Troitiño Díaz. The Role of the ESP Teacher in the In-company Training: An Experience in an Oil Exploration and Extraction \\ Company in Cuba. International Journal of Science, Technology and Society. Vol. 8, No. 3, 2020, pp. 29-33. \\ doi: $10.11648 /$ j.ijsts.20200803.11
}

Received: April 14, 2020; Accepted: May 3, 2020; Published: May 27, 2020

\begin{abstract}
Training is one of the organizational forms of postgraduate. In teaching English for specific purposes ESP it is very useful as it allows the student to be approached to the real scenario where he needs to communicate, among other functions. The teacher never loses his role but according to the scenario, it may include other skills that are not the ones they are used to display in the traditional class. Being a tutor in the workplace is very challenging. Sometimes teachers are scared of failing, as they have to face a technical vocabulary as well as some unforeseen situations which have to be handle with some expertise. The key is not to be afraid of these new experiences. Using the student's expertise in their field together with the teacher's skills may become a very powerful tool. This article goes into the different roles of the tutor as facilitator of the pedagogical process during this organizational form. The author of this paper wants to provide with some confidence to teachers while they are specializing in different ESP scenarios. That's why she has shared examples of a training that was carried out in an oil exploration and production company in the province of Matanzas through three performance tasks carried out in the workplace. This may be generalized to other contexts too.
\end{abstract}

Keywords: Training, English, Tutor, Company, Oil

\section{Introduction}

Training as an organizational form of professional development has multiple potentials that must be exploited in the appropriate work scenarios. Its training actions are aimed at updating, perfecting, systematizing and consolidating practical methodological skills in scenarios of the work activity, where the teacher serves as a tutor who monitors the performance of the work actions performed by the students (workers, industry specialists, directors etc.) [1]. In the teaching of English for specific purposes (IFE), training is very important, as it puts the student in contact with the real object of his daily activity at his job. The work of the tutor is essential but not the main one. This work aims to explain the different functions of the tutor during the training as well as describe an experience that was carried out in the Exploration Company - Production Center in Matanzas, Cuba.

\section{The Tutor}

In the teaching of IFE, the tutor must have vast knowledge of general English (GE) but in turn must know the field in which they will work with the students. In this sense, the main difference is that the tutor (teacher) is not the one who knows the main content to be treated, and the reason is obvious since IFE includes specific knowledge of the branch in which it works: business, mining, laws, oil and gas etc. The teacher is almost always trained in language skills only. That is why when an IFE training is carried out, students can learn more about the material they study or the content of the tutor. The transition from teacher to teacher tutor in training lies precisely in the fact that the teacher, as expressed, is not the one who exclusively possesses all the knowledge to be transmitted, but with his abilities, and mastery of functions and tasks inherent to the students is able to channel the 
student's knowledge giving rise to effective communication strategies in the scenario where it develops. The training is not characterized by having a large number of students, but the tutor works with 8 or 10 so that the feedback they can receive from each other comes at the precise moment in which unforeseen situations occur. [2, 3]

Roles of the Tutor in Training

The tutor in the work scenario assumes several roles at the same time: teacher, program designer and materials supplier, collaborator, researcher and evaluator. Below is a brief overview of each role:

a) Teacher: this is a role that is never lost in any context, the innate teacher skills are revealed in each of the following roles.

b) Program designer and material supplier: taking into account the needs and context where the training of the students will be conducted, the program and the materials are derived. It is difficult in most cases to find the most appropriate materials, materials that fit the work context and that the student sees in them a reference or guide to perform their daily work. That is why many times the tutor creates his own materials, grouping them and searching in different sources or writing his own when what is needed is not found. His role, of course, does not end here, he must evaluate the effectiveness of these materials during training and after finishing it.

c) Contributor: this role is of the utmost importance. The training tutor works many times in unknown terrain, moving from one job to another and each one has its own specificities. It is impossible for the tutor to master all the requirements and specialties and this is where collaboration comes into play. The tutor contacts students when designing materials and the training program that will take place. This collaboration can occur in several ways:

1. Simple cooperation where the tutor with the help of a specialist knows about the work and responsibilities of the training participants.

2. Specific cooperation where the collaboration between the tutor and the specialist is more extensive, this provides the tutor with all the labor content of the participants and the tutor because it gives the specialist the program to be addressed in the training. Thus the specialist of the branch where he goes to work provides an evaluation of the teaching materials that will be used. Thus raising their effectiveness at the time of use in the corresponding scenario but without escaping those unforeseen situations that may occur during the course of it.

3. Full cooperation: A specialist is chosen. This one has to be previously interviewed by the tutor evaluating their foreign language skills. He/She will conduct training with the tutor at all times, what is known as team teaching which is not necessary when GI is taught.

And returning to the tutor's roles:

a) Researcher: The tutor should have a marked interest in research methods that can be used to carry out various tasks such as the determination of needs, the design of training and the selection of materials. That is why the tutor must possess research skills and abilities, when the needs for a training are determined, it goes beyond the wishes of the specialist, an exhaustive study is made of what skills should be developed or continue to be perfected in the specialists in the labor context that concerns them.

b) Evaluator: The tutor together with the specialists evaluate not only the linguistic content but also the practical skills that are developed during the training. [4]

\section{Training Experience at the EPEPC (Oil Drilling and Extraction Company Center) Matanzas, Cuba}

\subsection{Performance Task 1 Varadero City Drilling Well}

The experience of a training carried out at the Petroleum Drilling and Extraction Company Center where several performance tasks were carried out in the labor scene of the specialists is presented below.

Before starting this training, a specific cooperation work was carried out, where the tutor and specialists jointly worked to determine if the content and performance tasks raised in the program really corresponded to the true learning needs of the participants in the program. In the training, here, the tutor is an active being who explores, questions and knows the work reality where he will interact. After several table work between tutor and specialists where the teaching materials prepared and selected by the tutor were also reviewed. Training began and one of the most complex scenarios was the performance task performed at the Varadero drilling well. This is where Chinese students and specialists interact as part of the Great Wall company working in Cuba. It is important to make reference that these areas are highly dangerous, so prior coordination and authorization is required to work in them, it is not exactly working in the place but if in the area near it, placing the student in a family land where he must interact in his daily work. This generates various emotions in the student, which can sometimes be contradictory. The student feels familiar with the area where he is and the specialists around them, being the tutor present because he finds support, he feels that at any time the language fails him in the communication he can help him. But at the same time the student feels fear of error, because in this context an error in communication can be of serious consequences when executing the actions in the drilling well. The tutor must be very careful in dealing with these feelings, and provide the student with the confidence necessary for him to accomplish the task with his support but in turn with that of the rest of the team. [5]

Teamwork in training is essential, the tutor is another member of this group and should be treated as equal and used 
as a means of change, the group exchanges and offers knowledge, shares experiences, experiences of their day to day actions that are enriched with each task they undertake. In this task the students had to describe the characteristics of the area to the Chinese specialists, specificities of the terrain, advantages and disadvantages that it presents for drilling, as well as possible methods to be used. Already in this field there is the well and in fact it is working, what is pursued with this task is to prepare the student for future joint work in the incessant search for possible drilling sites. The achievement of being able to work with Chinese specialists confronts the student with a regular work colleague but with a different accent and often a different way of organizing ideas by expressing them. The student is taught the correct form of communication in the English language but the communication is richer and of course in the real scenario there are expressions and words that may seem new due to the pronunciation of the speaker of another nationality. The tutor here plays a key role by intervening only when necessary, making the members of his team feel that he is there but that in turn the students have the freedom to express themselves and try to resolve the communication situation in the English language that was introduced with this performance task. [6] These students are able to explain and describe in the English language characteristics of the drilling process, give reasons why the drilling methods they present are the most appropriate and reach agreements with the foreign specialist.

After having developed this task, it is necessary to make reference that in the event of unforeseen situations in the real scenario the tutor must have a high level of preparation in the area where it is being developed, without reaching improvisation, many times you have to use resources from the pedagogical skills of the tutor, remembering that he is not an expert as explained above in all work areas where he should work. The process of preparation and cooperation, the work as a researcher and collaborator is vital before starting the training.

By being close to the oil rig, students explain the importance of controlling the pressure in the well to achieve a successful drilling. One of the dangers that threaten this success is precisely what is called blow-out (uncontrolled upwelling) or commonly blowout. The specialists explain that this can destroy the platform completely and cause serious damages and injuries to those who are working on it as well as damage to the environment, a total catastrophe that must be avoided. In addition, it was described how to prevent the occurrence of the this, using what they call blow-out preventer BOP (blowout preventer), in this particular the specialist in charge forgot the term so that another colleague without altering the presentation, intervened naturally facilitating the flow of exposure. In the oil industry there are terms like this one of BOP that have been standardized and specialists frequently use them instead of the Spanish term. However, pronunciation is not the most appropriate and it is important to work with it because an error in this context due to poor communication with the foreign specialist can be fatal.

When describing parts of the platform there was a term that students often forgot and this is the case of drill string (drill string) and this is the fundamental part that carries out the underground drilling. In this case, a platform was used (one that at that time was not working), but was useful for the student to have the real object to identify their essential parts. The work in that case required prior authorization to work on the site and supervisors to help the tutor in this more technical part.

\subsection{Performance Task 2 in the Company, Matanzas, Cuba}

Then in the company we worked on how to fill out an order to buy instruments to perform the drilling. The students here interact with the real models they need in their daily actions but they already have a higher level of understanding of the vocabulary that comes in the template. The work of the tutor here is in conjunction with them, that is, it is full cooperation, in the oil and gas industry many terms of English are used as they are in the English language that is why the specialist often dominates the term but not the pronunciation or the proper writing as he writes it as he pronounces it as already expressed. In this scenario, the tutor enters with his pronunciation skills to help specialists not only fill in the purchase format correctly but also pronounce them properly. Many times the communication with the provider is done by telephone so it must be very accurate.

In the same way, we work with the drilling report format, which is a document that the specialist works daily and it is very important. This one has to be completed in the English language without making mistakes that may affect the drilling process. This format was worked independently by the specialists as an individual task to achieve a higher level of improvement in filling them and that new questions arise by having more time for the study of these.

The involvement at all times of industry specialists, of real work materials and locations of the real scenario in performance tasks encourages creativity, imagination, innovation and their interest in the task. This is due to the clarity in the objectives by both parties and the high implication in its scope. From the beginning, an equitable distribution of responsibilities should be made, when interacting near the platform no specialist felt superior to another, so that communication flowed in the most natural way possible. [7]

The students felt very motivated because they knew that at the end of the training they could carry out their oral interactions with foreign specialists with additional language tools that allow them to understand and not use a translator, thus increasing their level as a professional in this industry.

\subsection{Performance Task 3 in the Oil Extraction and Exploration Center in Matanzas, Cuba Meeting Room}

Another performance task that was performed satisfactorily took place in the company meeting room. It explained the possible drilling methods to be carried out in 
the area previously treated. Instructions were given by the Cuban side and action was promised by the foreign party. It is important to note that these tasks were simulations of the work carried out by these specialists. Prior coordination was necessary to carry them out.

This part of coordination depending on the place is extremely important. There are companies where there are restrictions in different areas, safety equipment to be used etc. That is why, in the preparation of the training itself according to the performance tasks, the tutor and the specialists must anticipate what they will require prior authorization, so that when the time comes they will not be truncated because there is no required permission.

Returning to the meeting, there was a power outage for about half an hour, here the students increased their anxiety level because they could no longer help their digital presentations. That is why prior manual cards were prepared with the fundamental contents to be treated by them during the explanation of each drilling method. It would have been useful to have prepared a poster with digital information to increase student safety a bit. This teaching allowed us to improve in this aspect this performance task when there will be done in another company. The training has this flexibility; it is adjustable according to the context where it is applied but it also undergoes changes according to each application due to the experiences it generates with each task.

The self-assessment was used providing a guide of aspects to the student to be performed by themselves. The coevaluation was also used, where they had the opportunity to participate and give their criteria and opinions in relation not only to the work of their colleagues but also to the work of the tutor in the task, the fulfillment of their expectations and suggestions to improve in the following editions.

When interviewing executives of this company after completing the planned training, they said that the knowledge of these specialists in relation to specific terminology of the industry had risen significantly but also that they were already able to explain, describe and argue various processes that occur in it. They also noticed a change in attitude towards tasks where they had to interact orally with foreigners, previously if a translator was not hired they did not appear alone at the work meetings, which in turn represented a decrease in expenses for hiring translators and interpreters.

\section{Conclusions}

As it can be seen the role of the English teacher in these trainings is laborious and at the same time requires a high degree of specialization by the teacher. [8] Their functions do not deny that of the teacher who teaches English for general purposes but does require more refined skills. This training this time took place in the oil and gas industry but can be moved to any job following of course the rules established by it. Moving the classroom to the company is not exactly a training in itself, it would only be changing the scenario. This change of scenery makes the student feel closer to his position but in turn brings interruptions of the high command by having his subordinates within the company which deconcentrates and breaks with the dynamics of student learning. Training involves taking precise actions that this student in his role as a worker performs daily, perfecting those skills that he already possesses but needs to sharpen even more. The IFE field is very rich; the teacher can move through areas unknown to him. The cooperation described at the beginning in the design stage of the training program when determining the needs of specialists in their work scenario is of great relevance.

The selection, adaptation and use of real materials together with the work of the tutor and the specialists of the company are vital for the development of the training. [9]

It has been shown that the use of this organizational form of the postgraduate course for teaching IFE in its work context has more advantages than disadvantages. The key is step by step to meet all your requirements and improve it for future implementations in the same industry with different specialists or in a different industry.

The IFE tutor acquires endless knowledge in each training regarding the industry where it takes place while the specialists are updated and specialize in the English language. [10] Sometimes the tutor is younger than the group of specialists who will receive the training, this cannot become a disadvantage but the tutor must use it in favor of their own learning and that of the participants through their collaboration at different times of the preparation, execution and evaluation of it.

\section{References}

[1] Bernaza, G et al (2018). Professional improvement: move ideas and move further. Havana. First digital version.

[2] Bernaza, G. (2005). The teaching-learning process in postgraduate education, reflections, questions and proposals for innovation. Havana: Postgraduate Directorate of the MONTH, light printing, Havana, Cuba.

[3] Bernaza, G. (2015). Building pedagogical ideas about the postgraduate from the historical-cultural approach. Edited and printed in Mexico: University Publishing. Digital Edition. Pp. 57-62, 73-80, 122-123, 128-140.

[4] Troitiño, Dora. (2017). Training Program in English for Specific Purposes for the Oil and Gas Industry. Thesis presented as an option to the scientific degree of Doctor of Pedagogical Sciences. Havana Cuba.

[5] Hutchinson, T. \& Waters, A. (1987). English for Specific Purposes: A learner-centered approach. Cambridge University Press.

[6] Hyland, K. (2009) Specific Purposes Programs. In Long, H. M., \& Doughty, J. C. (Ed.). The Handbook of Language Teaching. (pp 201-217). Wiley-Blackwell.

[7] Johns, A. M. \& Dudley-Evans, T. (1991). English for Specific Purposes: International in Scope, Specific in Purpose. TESOL Quarterly 25: 2, 297-314. 
[8] Kim, D. (2008). English for Occupational Purposes: One Language Continuum.

[9] McDonough J (1984). ESP in perspective: A practical guide. London and Glasgow: Collins Educational.

[10] Paltridge, B., \& Starfield, S. (2013). The Handbook of English for Specific Purposes. Wiley- Blackwell.

[11] Short, J. A. (1983). Drilling: A Resource Book on Oil and Gas Well Drilling from Exploration to Completion. Pennwell Books: Oklahoma.
[12] Smoak, R. (April 2003). What is English for Specific Purposes. English Teaching Forum. P 22-27.

[13] Widdowson, H. G. (1983). Course design and methodology. In Learning Purpose and Language Use (pp. 80-104). OUP.

[14] Widdowson, H. G. (1984). English for specific purposes. In Explorations in Applied Linguistics 2 (pp. 188-190). OUP. 